\title{
Accuracy of a digital skinfold system for measuring skinfold thickness and estimating body fat
}

\author{
Teresa F. Amaral ${ }^{1,2 *}$, Maria Teresa Restivo², Rita S. Guerra ${ }^{2}$, Elisa Marques ${ }^{3}$, Maria F. Chousal ${ }^{2}$ \\ and Jorge Mota ${ }^{3}$ \\ ${ }^{1}$ Faculty of Nutrition and Food Sciences, University of Porto, Rua Dr Roberto Frias, 4200-465 Porto, Portugal \\ ${ }^{2}$ UISPA-IDMEC, Faculty of Engineering, University of Porto, Rua Dr Roberto Frias, 4200-465 Porto, Portugal \\ ${ }^{3}$ Research Centre in Physical Activity, Health and Leisure, Faculty of Sport Sciences, University of Porto, \\ Rua Dr Plácido Costa 91, 4200-450 Porto, Portugal
}

(Received 11 February 2010 - Revised 16 August 2010 - Accepted 25 August 2010 - First published online 7 December 2010)

\begin{abstract}
The use of skinfold thickness measurements to evaluate the distribution of subcutaneous adipose tissue and to predict body fat has recognised advantages. However, the different types of skinfold calliper available present limitations that make them unattractive and perhaps less used in daily practice. The purpose of the present study was to evaluate the accuracy and functionality of a new digital skinfold system, the Liposoft 2008 + Adipsmeter V0 (LA), for measuring skinfold thickness and determining body fat proportion (\%BF). Skinfold thickness measurements made by the LA were compared with those obtained with a Harpenden $(\mathrm{H})$ calliper from two samples of adults $(n$ 45) and older adults ( $n$ 56) in a university-based cross-sectional study. A comparison was also conducted between estimated \%BF from skinfolds and dual-energy X-ray absorptiometry. Bland and Altman plots show that skinfolds measured by the LA and $\mathrm{H}$ calliper are in high agreement, with a mean difference of $0.3(95 \% \mathrm{CI}-3 \cdot 1,3 \cdot 4) \mathrm{mm}$. In regard to the $\% \mathrm{BF}$ estimated from LA and $\mathrm{H}$ skinfolds measurement, the LA produced a similar approximation to dual-energy X-ray absorptiometry $\% \mathrm{BF}$, with a mean difference of $0 \cdot 2(95 \% \mathrm{CI}-0 \cdot 8,1 \cdot 2) \%$, compared with $\% \mathrm{BF}$ obtained with the $\mathrm{H}$ calliper. The LA system is an accurate instrumentation and represents an innovation in the evaluation of skinfold thickness and body composition based on anthropometric measurement.
\end{abstract}

Key words: Digital skinfold systems: Body fat: Skinfold thickness: Callipers

Body fat proportion $(\% \mathrm{BF})$ is a major issue in health. Recent studies estimate that $23 \cdot 2 \%$ of the world's adult population is pre-obese and $9.8 \%$ is obese ${ }^{(1)}$. In Europe, this figure is even higher. According to the $\mathrm{WHO}^{(2)}$, over $50 \%$ of the European adult population is pre-obese or obese. The use of skinfold thickness measurement to evaluate regional and body distribution of subcutaneous adipose tissue and to predict body fat has become one of the most widely used anthropometric techniques in nutritional status and body composition assessment ${ }^{(3)}$. It is based on the two-compartment model which divides the body into fat mass and fat-free mass ${ }^{(4)}$. Other, more sophisticated methods for estimating body fat, namely dual-energy X-ray absorptiometry (DXA), are not convenient for large-scale field studies or for routine practice ${ }^{(5)}$, as the equipment is expensive and not portable.

The skinfold thickness technique is a highly informative, non-invasive, portable and inexpensive bedside and field method to determine body fat. However, the different types of skinfold calliper available present some limitations that make them unattractive and perhaps less used in daily practice. Some models, recognised in the specialised literature, have a rotating needle over an analogue scale which makes measurement difficult during the established measuring time interval of $2-4 \mathrm{~s}^{(4)}$ after pressuring the tissue, according to the designed modus operandi. The technical procedure can be compromised by the reading of the needle position as well as the subjectivity associated with the mental counting of the pre-defined time interval. In addition, because measurement values need to be manually annotated in those available models, the evaluation procedure is frequently interrupted, therefore it becomes more time consuming or requires a second technician to annotate the data. In any case, both solutions have intrinsic error sources.

To predict body density and $\% \mathrm{BF}$, regression equations are required after the skinfold thickness measurement. In fact, the large number of equations available requires the

Abbreviations: \%BF, body fat proportion; DXA, dual-energy X-ray absorptiometry; H, Harpenden; LA, Liposoft $2008+$ Adipsmeter V0. 
selection of the most appropriate, based on its validity within the population under study ${ }^{(6)}$. These calculations are an additional task, which make the assessment of body fat even more difficult and time consuming.

Therefore, the development of a new, more accurate instrumentation for \%BF determination using skinfold thickness measurement, which also has data-recording capacity, is currently required. The purpose of the present study was to evaluate the accuracy and the functionality of a new digital skinfold system, the Liposoft $2008+$ Adipsmeter V0 (LA), for measuring skinfold thickness and determining body fat proportion.

\section{Methods}

\section{Subjects and design}

The LA system comprises of a modified Harpenden (H) calliper with digital skinfold thickness-reading capacity (Adipsmeter V1.0) incorporating wireless transmission for a software application (Liposoft 2008) and predictive equations for the body density and the \%BF calculation ${ }^{(7)}$.

An automatic measurement of skinfold thickness was achieved using a traditional $\mathrm{H}$ calliper (the most recommended calliper to be used $)^{(8,9)}$ and integrating digital sensorisation and wireless communication capabilities with a LabVIEW software application. This application follows the recommended skinfold measurement protocol $^{(4,8,10,11)}$

To obtain these new features, slight mechanical changes were introduced. The old dial mechanical indicator was replaced by a simple, inexpensive and linear miniaturised encoder easily interfaced with a computer, for a contactless skinfold thickness measurement. The wireless communication is based on ZigBee technology. The wireless receiver used for communication with any personal computer is of universal serial bus type. The system is inexpensive, has $9 \mathrm{~h}$ of autonomy and can be easily recharged.

The information acquired is digitally recorded in a system-integrated database and could be used later for following up individual progress. The common anthropometrist reading errors due to measurement with a moving needle in front of an analogue scale within a mental time interval counting are eliminated. So, the automatic measurement system is not so demanding and requires less of a technician's skills and time.

Right after performing the skinfold thickness measurement, the technician can choose the appropriate body density and \%BF predictive equation and promptly determine the $\% \mathrm{BF}$. The system offers an intuitive route through the procedure using an established sequence ${ }^{(8-10)}$. The LA application data recording process permits visual graphic inspection during measurement and so it helps to control the measurement quality, namely the differences between measurements. In fact, any skinfold thickness measurement considered unreliable by the technician can be erased and a new measurement can be performed. The LA integration of a database system allows the recording and continuous updating of data for each individual. Finally, if desired, it is possible to print a test report and to export the test data.

The accuracy of skinfold thickness measurements, carried out by the LA, was compared with those obtained with a non-modified $\mathrm{H}$ calliper, from two samples of adults and older adults in a university-based cross-sectional study. A comparison was also conducted between estimated and DXA-\%BF.

The adult sample had forty-five individuals, recruited on a voluntary basis within some faculties from the University of Porto. The older adult sample comprised fifty-six individuals engaged in an exercise programme at the Physical Activity, Health and Leisure Research Centre of the Sports Faculty - University of Porto. The study was conducted according to the guidelines laid down in the Declaration of Helsinki ${ }^{(12)}$. All the participants were informed of the study purposes as well as the different procedures. Verbal informed consent from all the subjects was witnessed and formally recorded.

\section{Data collection}

Skinfolds were measured with the LA and with an $\mathrm{H}$ calliper with similar resolutions, in a random order. Measurements were taken along the right side of the body and for three consecutive times with each calliper, according to the International Standards for Anthropometric Assessment recommendations ${ }^{(9)}$, using triceps, subscapular, biceps, iliac crest and front thigh sites. Height (m) was measured with the individuals barefooted, using a stadiometer (Seca 708; Seca Limited, Birmingham, UK), with a resolution of $0.001 \mathrm{~m}^{(4)}$. Body mass $(\mathrm{kg})$ was measured by a scale (Seca) (resolution of $0 \cdot 1 \mathrm{~kg}$ ) with the individuals barefooted and wearing light clothes ${ }^{(4)}$. All the measurements were obtained at the same visit.

Reference \%BF was evaluated in a three-compartment model with DXA equipment (Hologic QDR-4500). Body composition was estimated by QDR Software for Windows XP, version 12.4 (Hologic, Inc., Bedford, MA, USA). All scans were performed by the same technician using standard procedures as described in the Hologic Users Manual. Complete body DXA scans were made with a scan time of approximately $8 \mathrm{~min}$. The \%BF determined by the system represents (fat mass (g)/total mass $(\mathrm{g}) \times 100)(\mathrm{DXA}-\% \mathrm{BF})$. Both the callipers and the DXA were previously calibrated.

\section{Data analysis}

For the adult sample, \%BF derived from skinfold measurement with the LA system and the $\mathrm{H}$ calliper was calculated using the Peterson et $a l^{(13)}$ equation (Peterson-\%BF), developed and validated with a four-compartment model. 
The $\% \mathrm{BF}$ of the older adult sample was predicted with the body density Visser et al. ${ }^{(14)}$ regression equation and transformed into \%BF with the Brozek formula ${ }^{(15)}$ (Visser-\%BF), which were both developed and validated against a two-compartment model. The mean values of DXA-\%BF were compared with Coin et al. ${ }^{(16)}$ reference values, according to sex and age.

Means and standard deviations were calculated for the quantitative and continua variables. The normal distribution of the variables was tested using the Kolmogorov-Smirnov test. Association between the skinfold measurements from the LA system and $\mathrm{H}$ callipers was evaluated by Pearson's correlation coefficients $(r)$. Association between the Visser-\%BF and Peterson-\%BF (either using the LA system or $\mathrm{H}$ callipers) with DXA-\%BF was evaluated by Pearson's or Spearman's correlation coefficients $(r)$ considering the normality of data distribution.

The mean and SD of the differences in skinfold thickness measurement between the LA system and those obtained with $\mathrm{H}$ callipers were calculated as LA minus $\mathrm{H}$. The same calculations were conducted for the \%BF obtained by the LA system and $\mathrm{H}$ equipment and by the appropriated equations. Mean difference and the SD of the differences between the DXA-\%BF and \%BF estimated from both skinfold measurement equipments were also calculated. The differences were compared using the paired-samples $t$ test or Wilcoxon test, according to the data distribution.

A Bland \& Altman $\operatorname{plot}^{(17)}$ for difference against mean for all skinfold thickness measurements from the LA system and $\mathrm{H}$ callipers was used to compare the accuracy and level of agreement for the skinfolds thickness measured by both methods. A second Bland and Altman plot for the comparison of the accuracy and level of agreement of the LA and $\mathrm{H}$ system for the \%BF estimates was also prepared.

Total error between Peterson- $\% \mathrm{BF}$ and Visser- $\% \mathrm{BF}$ towards DXA-\%BF was also calculated ${ }^{(5)}$ :

$$
\sqrt{\sum\left(\left(Y_{1}-Y_{2}\right)^{2} / n\right)}
$$

where $Y_{1}$ is the predicted value, $Y_{2}$ is the actual value and $n$ is the number of paired observations.

The adopted level of statistical significance was $P=0 \cdot 05$. The significance levels quoted are two sided. All the statistical analyses were carried out using the Software Package for Social Sciences for Windows, version 14.0 (SPSS, Inc., Chicago, IL, USA).

\section{Results}

Descriptive statistics of the adults and older adult samples are presented in Table 1, showing that these two groups are heterogeneous regarding the studied characteristics. The results show that the majority of skinfolds thickness obtained by the LA system are similar to those obtained with $\mathrm{H}$ callipers. The estimation of \%BF from DXA, the $\mathrm{LA}$ system and $\mathrm{H}$ measurement converted in \%BF by regression equations is also presented in Table 1 . The DXA-\%BF value was within the tabled body fat reference

Table 1. Characteristics of the samples

(Mean values and standard deviations)

\begin{tabular}{|c|c|c|c|c|c|c|c|c|}
\hline \multirow[b]{3}{*}{ Variable } & \multicolumn{4}{|c|}{ Adults } & \multicolumn{4}{|c|}{ Older adults } \\
\hline & \multicolumn{2}{|c|}{ Women (n 28) } & \multicolumn{2}{|c|}{ Men $(n 17)$} & \multicolumn{2}{|c|}{ Women (n 35) } & \multicolumn{2}{|c|}{ Men ( $n$ 21) } \\
\hline & Mean & SD & Mean & SD & Mean & SD & Mean & SD \\
\hline Age (years) & $40 \cdot 8$ & $12 \cdot 0$ & 25.4 & 3.4 & $73 \cdot 0$ & $6 \cdot 0$ & $70 \cdot 1$ & 4.6 \\
\hline Height (m) & 1.59 & 0.06 & 1.77 & 0.05 & 1.53 & 0.06 & $1 \cdot 68$ & 0.05 \\
\hline Wt $(\mathrm{kg})$ & $59 \cdot 0$ & $9 \cdot 4$ & 78.4 & 11.7 & $61 \cdot 1$ & $7 \cdot 2$ & $76 \cdot 8$ & 9.6 \\
\hline \multicolumn{9}{|l|}{ Skinfolds (mm) } \\
\hline \multicolumn{9}{|l|}{ LA system } \\
\hline Triceps & 21.4 & $6 \cdot 2$ & $13 \cdot 9$ & $5 \cdot 2$ & $20 \cdot 4$ & $5 \cdot 3$ & $11 \cdot 0$ & $2 \cdot 9$ \\
\hline Biceps & $13 \cdot 7$ & $6 \cdot 4$ & 8.9 & $5 \cdot 0$ & $16 \cdot 3$ & $4 \cdot 6$ & 9.5 & $3 \cdot 0$ \\
\hline Subscapular & $15 \cdot 8$ & $8 \cdot 2$ & $12 \cdot 6$ & $5 \cdot 2$ & $18 \cdot 7$ & 7.9 & $15 \cdot 1$ & $3 \cdot 3$ \\
\hline Iliac crest & $15 \cdot 8$ & $6 \cdot 0$ & 14.4 & $7 \cdot 3$ & $18 \cdot 9$ & $6 \cdot 0$ & $15 \cdot 0$ & 4.4 \\
\hline Front thigh & $32 \cdot 6$ & $9 \cdot 8$ & $17 \cdot 9$ & 8.5 & & & & \\
\hline \multicolumn{9}{|l|}{ Harpenden callipers } \\
\hline Triceps & $21 \cdot 7$ & $5 \cdot 8$ & 14.4 & 5.4 & $20 \cdot 8$ & $5 \cdot 3$ & $11 \cdot 2$ & $3 \cdot 1$ \\
\hline Biceps & $14 \cdot 3$ & $6 \cdot 5$ & $9 \cdot 3$ & $5 \cdot 3$ & $16 \cdot 6$ & $4 \cdot 1$ & $9 \cdot 7$ & $2 \cdot 8$ \\
\hline Subscapular & $16 \cdot 1$ & $8 \cdot 6$ & $13 \cdot 1$ & $5 \cdot 4$ & $19 \cdot 1$ & 7.5 & $15 \cdot 0$ & $3 \cdot 1$ \\
\hline Iliac crest & $16 \cdot 0$ & $6 \cdot 0$ & $14 \cdot 8$ & $7 \cdot 0$ & $18 \cdot 6$ & 5.6 & $14 \cdot 8$ & 4.2 \\
\hline Front thigh & $33 \cdot 0$ & $8 \cdot 7$ & $18 \cdot 7$ & 8.7 & & & & \\
\hline \multicolumn{9}{|l|}{$\mathrm{BF}(\%)$} \\
\hline DXA & 32.59 & 5.97 & $20 \cdot 27$ & $6 \cdot 85$ & 37.49 & 4.80 & $25 \cdot 86$ & 4.38 \\
\hline LA system ${ }^{\star}$ & $34 \cdot 31$ & $5 \cdot 75$ & $22 \cdot 00$ & $5 \cdot 72$ & 41.41 & 1.98 & $29 \cdot 67$ & $1 \cdot 21$ \\
\hline Harpenden callipers ${ }^{*}$ & 34.50 & 5.76 & 22.55 & 5.67 & 41.66 & 1.80 & 29.69 & 1.21 \\
\hline
\end{tabular}

LA, Liposoft 2008 + Adipsmeter V0; BF, body fat; DXA, dual-energy X-ray absorptiometry.

*\%BF obtained from LA system and Harpenden skinfolds measurement and equations: Peterson et al. ${ }^{(13)}$ equation for the adult sample and Visser et al. ${ }^{(14)}$ and Brozek et al. ${ }^{(15)}$ for the older adult sample. 
Table 2. Skinfolds and percentage body fat differences between the Liposoft 2008 + Adipsmeter VO (LA) system and Harpenden $(\mathrm{H})$ callipers $^{*}$

(Mean values and standard deviations)

\begin{tabular}{lccccc}
\hline & \multicolumn{2}{c}{ Women } & & \multicolumn{2}{c}{ Men } \\
\cline { 2 - 3 } \cline { 5 - 6 } & Mean & SD & & Mean & SD \\
\hline Adults $(n)$ & 28 & & \multicolumn{2}{c}{17} \\
$\quad$ Skinfolds $(m m)$ & & & & \\
$\quad$ Triceps & -0.28 & 1.29 & & -0.55 & 0.79 \\
$\quad$ Biceps & -0.56 & 1.55 & & -0.37 & 1.00 \\
$\quad$ Subscapular & -0.37 & 0.88 & & -0.57 & 0.80 \\
lliac crest & -0.24 & 1.17 & & -0.38 & 1.62 \\
$\quad$ Front thigh & -0.34 & 2.18 & & -0.86 & 1.27 \\
Body fat (\%) & -0.19 & 0.52 & & -0.55 & 0.54 \\
Older adults $(n)$ & \multicolumn{2}{c}{35} & & & 21 \\
Skinfolds $(\mathrm{mm})$ & & & & \\
$\quad$ Triceps & -0.33 & 1.46 & & -0.21 & 0.46 \\
$\quad$ Biceps & -0.33 & 1.77 & & -0.20 & 0.66 \\
$\quad$ Subscapular & -0.40 & 1.86 & & 0.06 & 1.12 \\
$\quad$ lliac crest & 0.29 & 2.80 & & 0.17 & 1.66 \\
Body fat (\%) & -0.24 & 0.81 & -0.02 & 0.27 \\
\hline
\end{tabular}

*Differences were calculated as LA minus $\mathrm{H}$.

values for adult women and older sample, while it was slightly higher for the adult men ${ }^{(16)}$.

Means and SD for skinfolds and \%BF differences between the LA system and $\mathrm{H}$ callipers are displayed in Table 2, stratified by sex and age groups. The mean differences for skinfolds thickness are small; all are lower than $-0.86 \mathrm{~mm}$ with a SD of $<2.80 \mathrm{~mm}$. The SD of skinfolds thickness differences are slightly higher for skinfolds measured in females than for males, except for the iliac crest skinfold in the adult women group. The SD of these differences are also slightly higher for older women than for the adult women. Concerning the mean \%BF differences, the results show that LA values are similar to those obtained with $\mathrm{H}$ callipers. The mean differences are small, under $-0 \cdot 24 \%$, with a very low SD, below $0 \cdot 81 \%$ BF (Table 2).
Bland \& Altman plots ${ }^{(17)}$ for difference against mean for all skinfold thickness measurements and also for $\% \mathrm{BF}$, from the LA system and $\mathrm{H}$ callipers (Figs. 1 and 2), show that both skinfolds and calculated \%BF obtained with the LA system and $\mathrm{H}$ callipers are in high agreement, revealing the accuracy of the LA system.

For the skinfold thickness measurement with the LA system and $\mathrm{H}$ callipers (Fig. 1), the dispersion of values is uniform with a slight rise when skinfolds thickness increases. The mean value for the difference between the two instruments is very low, $0.3 \mathrm{~mm}$, with small limits of agreement between the measurements $(-3 \cdot 1$ to $3.4 \mathrm{~mm})$. A strong association was found between measurements from the LA system and $\mathrm{H}$ callipers; correlation coefficients for each measured skinfold thickness were all above $r 0.91(P<0.001)$

The difference against mean for $\% \mathrm{BF}$ estimates from the LA system and $\mathrm{H}$ measurement and equations (Fig. 2) also shows that $\% \mathrm{BF}$ estimated by both methods are in high agreement, confirming the accuracy of the LA system. For the adult sample, the dispersion of values is uniform with a slight decrease when skinfolds thickness measurements increase. For the older adult sample, the opposite is observed. The mean value for the difference between the $\% \mathrm{BF}$ from the two instruments is very low, $0 \cdot 2 \%$, with small limits of agreement between measurement $(-0.8$ to $1 \cdot 2 \%)$. Percentage BF predicted by the LA system and $\mathrm{H}$ callipers is strongly correlated in the adult group ( $r$ 0.99, $P=0.01)$ and the same was observed for the older adult group $(r 0 \cdot 98, P=0 \cdot 01)$.

Considering the DXA- $\% \mathrm{BF}$ as the criterion, the new digital system instrumentation LA leads to a similar approximation in the \%BF evaluation for adults and older adults, in relation to the traditional $\mathrm{H}$ skinfold calliper (Table 3). The total error between DXA-\%BF and Peterson-\%BF was equal to $3 \cdot 1 \%$ for skinfold measurement carried out with the LA system and equal to $3.4 \%$ using the $\mathrm{H}$ calliper for

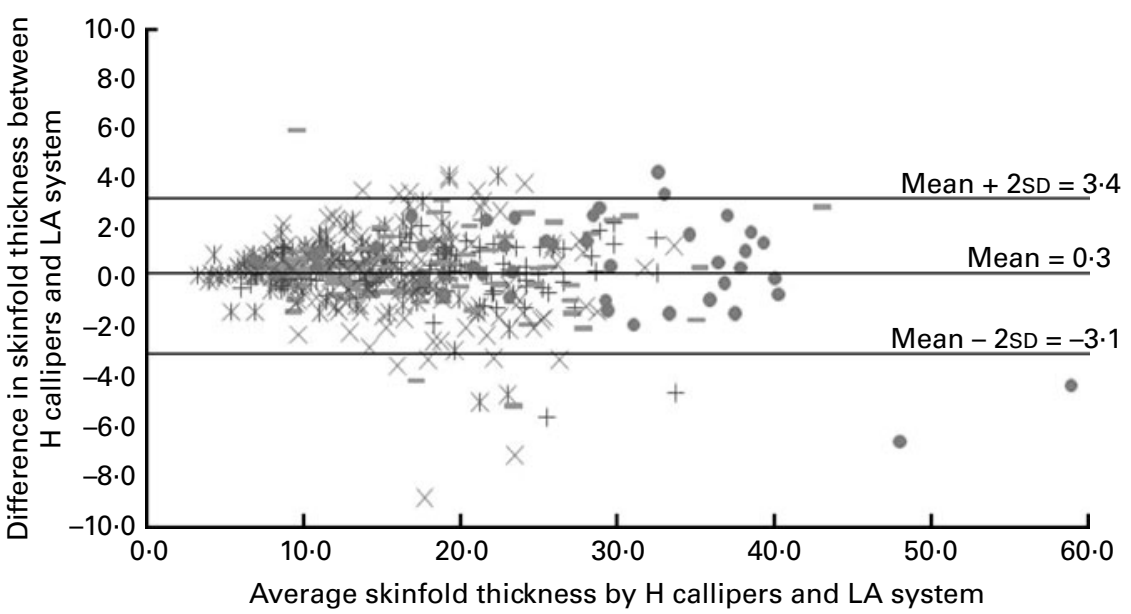

Fig. 1. Bland and Altman plot for difference against mean for skinfold thickness measurements (mm) from the Liposoft $2008+$ Adipsmeter V0 (LA) and Harpenden $(\mathrm{H})$ callipers. + , Triceps; $*$, biceps; - , subscapular; $\times$, iliac crest; $\bullet$, front tight. 


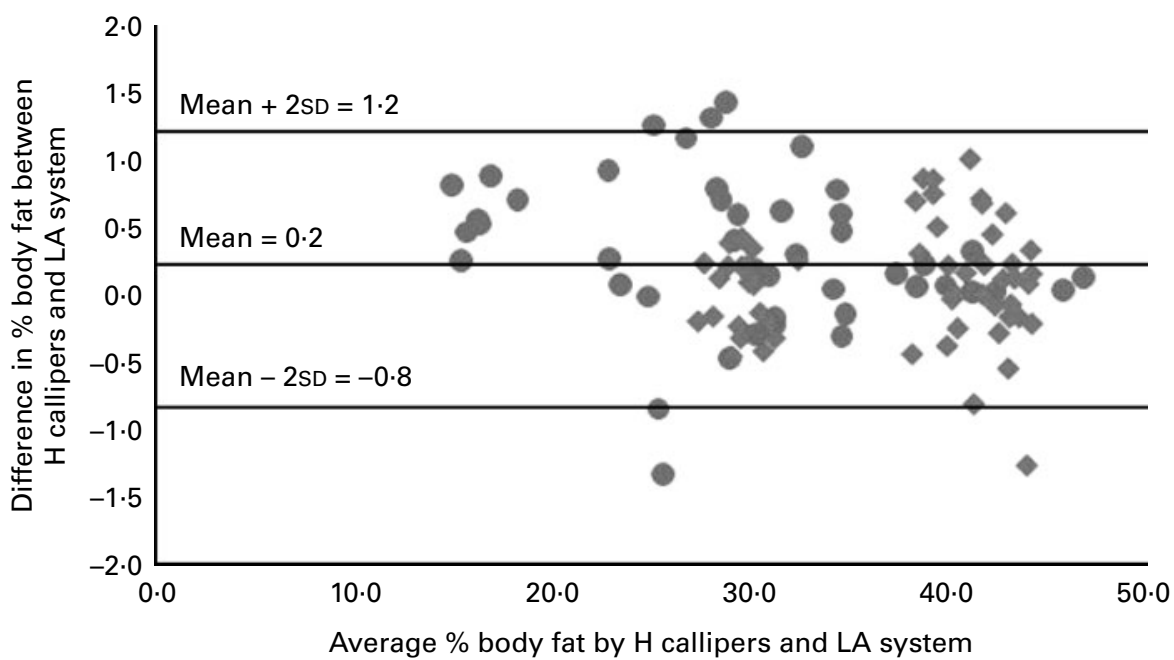

Fig. 2. Bland and Altman plot for difference against mean for \% body fat estimate from the Liposoft $2008+$ Adipsmeter Vo (LA) and Harpenden (H) callipers. $\bullet$, Adults; $\diamond$, older adults.

the adult sample. For the older group, the total error between DXA-\%BF and LA Visser-\%BF was equal to $5 \cdot 2 \%$ and between DXA- $\% \mathrm{BF}$ and $\mathrm{H}$ Visser- $\% \mathrm{BF}$ was equal to 5.4\% (Table 3).

A strong correlation coefficient was found between DXA-\%BF, LA Peterson-\%BF $(r 0 \cdot 95, P=0 \cdot 01)$ and H Peterson-\%BF $(r$ 0.94, $P=0.01)$. Despite this high association, results showed significant differences between the mean value from DXA- $\% \mathrm{BF}$ and from Peterson- $\% \mathrm{BF}$ for both sexes $(P<0.05)$ (Table 3). Strong associations were also found between DXA- $\% \mathrm{BF}$ and Visser- $\% \mathrm{BF}$ from the LA system $(r 0 \cdot 90, P=0 \cdot 01)$ and $\mathrm{H}$ callipers $(r 0 \cdot 90, P=0 \cdot 01)$. The mean DXA-\%BF was significantly lower than that calculated using the LA system $(P<0.001)$ and $\mathrm{H}$ skinfold thickness measurement $(P<0 \cdot 001)$ (Table 3).

\section{Discussion}

The main goal of the present study was to evaluate the accuracy of the LA system for measuring skinfold thickness and estimating body fat on adults and older adults.
The small magnitude of differences, the low SD of these differences and the narrow limits of agreement from Bland and Altman plots show that that the new LA digital system is in agreement with the $\mathrm{H}$ skinfold calliper for serial measurements of different skinfolds and for \%BF calculations in the same individual. These results support the LA digital system accuracy.

To our knowledge, only few studies until now have assessed the performance and accuracy of using different skinfold calliper models on skinfolds thickness and \%BF estimation. The differences in samples and techniques used between studies further limit direct comparisons. Burget \& Anderson ${ }^{(18)}$ compared triceps skinfold measurement between the McGaw and Lange callipers in ninetyone adults and fourteen obese adult patients and found a median difference between the callipers of $8 \%$. In the present study, we observed a lower median difference $(2 \cdot 0 \%)$ between the LA system and $\mathrm{H}$ callipers for the triceps skinfold measurement of the adult sample, which can be regarded as positive. Lohman et al. ${ }^{(19)}$ studied the effect of various skinfold callipers (Harpenden, Holtain, Lange

Table 3. Body fat (\%) differences and total error between Liposoft $2008+$ Adipsmeter V0 (LA) system, Harpenden $(\mathrm{H})$ callipers and dual-energy X-ray absorptiometry (DXA) (Mean values and standard deviations)

\begin{tabular}{|c|c|c|c|c|c|}
\hline & \multicolumn{2}{|c|}{ Women } & \multicolumn{2}{|c|}{ Men } & \multirow[b]{2}{*}{ Total error } \\
\hline & Mean & SD & Mean & SD & \\
\hline Adults $(n)$ & \multicolumn{2}{|c|}{28} & \multicolumn{2}{|c|}{17} & \\
\hline LA Peterson-\%BF - DXA-\%BF† & $1 \cdot 73^{\star}$ & 2.84 & $1.73^{\star}$ & $2 \cdot 38$ & $3 \cdot 1$ \\
\hline H Peterson-\%BF - DXA-\%BF† & $1.92^{*}$ & $2 \cdot 83$ & $2 \cdot 28^{\star}$ & $2 \cdot 67$ & 3.4 \\
\hline Older adults $(n)$ & \multicolumn{2}{|c|}{35} & \multicolumn{2}{|c|}{21} & \\
\hline LA Visser-\%BF - DXA-\%BF† & $3 \cdot 92^{\star \star}$ & 3.47 & $3 \cdot 80^{\star \star}$ & $3 \cdot 78$ & $5 \cdot 2$ \\
\hline H Visser-\%BF - DXA-\%BFt & $4 \cdot 17^{\star \star}$ & 3.54 & $3 \cdot 82^{\star *}$ & 3.68 & 5.4 \\
\hline
\end{tabular}

$\%$ BF, \%body fat.

Mean values were significantly different: ${ }^{*} P<0.05$, ${ }^{*} P<0.001$.

† Calculated by using paired-samples $t$ test for adult data and Wilcoxon test for older adult data (two sided). 
and Adipometer), the examiner technique and skinfold prediction equations in female university athletes. The results suggested that for any given prediction equation, the range in mean \% BF due to calliper-investigator combinations was $7 \%$.

Given that body composition changes are clearly related to the ageing process, several mechanisms could influence the precision of non-invasive methods, as in skinfold thickness measurement. To the best of our knowledge, no previous studies have assessed the performance and accuracy of the skinfold calliper among older adults, reinforcing the scope of the present results.

The new LA digital system instrumentation led to similar $\%$ BF evaluation for adults and older adults, relatively to the traditional $\mathrm{H}$ skinfold calliper. With regard to the results for both samples, a strong association was found between the DXA- $\%$ BF and \%BF estimation by skinfold and conversion equations, showing that these two methods are in very close agreement. Although the Peterson- $\%$ BF for the adult sample and the Visser-\%BF for the older adult sample produced slightly higher body fat estimation compared with DXA-\%BF, these differences could be attributable to the regression equations used.

Despite the fact that methodological differences compromise direct comparisons, previous studies comparing \%BF from skinfold-based equations to DXA-\%BF in healthy adult Caucasians ${ }^{(3,20-22)}$ also report high correlations between these techniques ${ }^{(21)}$. They depict significant differences between them as well, either overestimated ${ }^{(20,21)}$ or underestimated ${ }^{(3)}$. Stewart \& Hannan ${ }^{(20)}$ applied skinfold equations to a sample of twenty-four athletes and noted a total error of $2.9 \%$, slightly lower than the total error in the present study. Johansson et al. ${ }^{(21)}$ found a strong correlation between \%BF determined by DXA and skinfold thickness ( $r$ 0.81) in adult men (25-59 years old), but lower than those found in the present study. They also verified that DXA yielded a significantly lower mean fat content compared with skinfold thickness measurement, which is comparable to the present findings. However, Jackson et $a l^{(3)}$ cross-validated the Jackson/Pollock equations on a sample of 1129 young men and women, using DXA as the referent criterion for $\% \mathrm{BF}$ and concluded that prediction equations based on skinfold measurement underestimated $\%$ BF by $1.3 \%$ in men and $3.0 \%$ in women. Sardinha et $a l^{(22)}$, in a study conducted among sixty-two men, 37.6 (SD 2.9) years old, found a slightly weaker association for the skinfold thickness $\% \mathrm{BF}$ predicted by the Jackson/Pollock equation ( $r$ 0.87) and DXA-\%BF compared with the present results. They also found a higher SE for the $\% \mathrm{BF}$ estimation (3.7\%) as well as for $\% \mathrm{BF}$ predicted by the Durnin/Womersley equation $(r 0.85)$, where the SE of estimation was $3.9 \%$.

Considering healthy Caucasian older adults, few studies have assessed the validity of skinfold thickness in predicting $\% \mathrm{BF}$, having $\mathrm{DXA}-\% \mathrm{BF}^{(23,24)}$ as the reference method. Different population characteristics bring further difficulty to comparisons between studies. Haapala et al. ${ }^{(23)}$ compared skinfold thickness measurement with DXA in a sample of ninety-three women (62-72 years old) and found a stronger association between skinfold method and DXA-\%BF ( $r$ 0.94) than those found in the present study. However, the skinfold thickness measurement resulted in a significant error of -0.7 (SD 3.0$) \mathrm{kg}$ as well. Ravaglia et $a{ }^{(24)}$ estimated \%BF in sixty-seven men (20-95 years old) using skinfolds. Percentage BF, predicted by skinfold measurement and equations, underestimated DXA- $\% \mathrm{BF}$ in the group aged $>80$ years, contrary to the present findings, where skinfold measurements and regression equations overestimated DXA- $\%$ BF.

The lack of a random sample selection can be recognised as a study limitation. As participants were recruited on a convenience basis, care should be taken in extrapolating the findings for other age groups and for frail individuals, as well as for those less physically active and for obese individuals.

The present study provided evidence that the LA system is an accurate instrumentation and represents an innovation in the evaluation of skinfold thickness and body composition based on anthropometric measurement. One of the innovations of the LA system is the digital information acquisition of the measurement at a predefined time interval of 2-4s, according to the described methodology ${ }^{(8,10,11)}$. In the available analogical skinfold models, this time interval counting, readout of the needle position and its manual registration were subjectively performed by the technician and are now performed digitally and automatically. As the equipment is digitally sensorised, it not only facilitates skinfold thickness reading but also instantaneously records, stores and analyses data, while the wireless transmission of data in a portable way allows an instantaneous \%BF evaluation. So, the test is faster and probable sources of measurement bias are avoided. In fact, the LA system solved some of the intrinsic problems of the skinfold thickness technique measurement.

The authors believe that these innovating features will allow a quicker and broader utilisation of skinfolds. This may also have positive implications for non-clinical and for general use.

\section{Acknowledgements}

The present research received no specific grant from any funding agency in the public, commercial or non-profit sectors. E. M. was supported by a doctoral grant from FCT-MCTES (SFRH/BD/36319/2007) and R. S. G. was supported by a research grant from FCT-MCTES (POCTI/ISFL/ 416-10), within IDMEC - Pólo FEUP. T. F. A., M. T. R., M. F. C. and J. M. designed the study. T. F. A., R. S. G. and E. M. performed the data collection. T. F. A. and R. S. G. conducted data analysis. All the authors contributed to the drafting of the paper. The authors have no conflict of interest. 


\section{References}

1. Kelly T, Yang W, Chen CS, et al. (2008) Global burden of obesity in 2005 and projections to 2030. Int J Obes (Lond) 32, $1431-1437$.

2. European Parliament (2008) European Parliament resolution of 25 September 2008 on the White Paper on Nutrition, Overweight and Obesity-Related Health Issues (2007/ 2285(INI)) P6_TA(2008)0461.

3. Jackson AS, Ellis KJ, McFarlin BK, et al. (2009) Cross-validation of generalized body composition equations with diverse young men and women: the Training Intervention and Genetics of Exercise Response (TIGER) Study. $\mathrm{Br} \mathrm{J}$ Nutr 101, 871-878.

4. Lee RD \& Nieman DC (2007) Anthropometry. In Nutritional Assessment, 4th ed., pp. 169-221 [RD Lee, editor]. Boston, MA: McGraw Hill Higher Education.

5. Heymsfield SB, Lohman TG, Wong Z, et al. (2005) Statistical methods. In Human Body Composition, 2nd ed., chapter 11, pp. 151-160 [SB Heymsfield, editor]. Champaign, IL: Human Kinetics.

6. Bemben MG, Massey BH, Bemben DA, et al. (1998) Agerelated variability in body composition methods for assessment of fat and fat-free mass in men aged 20-74 years. Age Ageing 27, 147-153.

7. Restivo MT, Amaral TF, Mendes JG, et al. (2009) Porto University. Patent no. 103721 Conceded 23/11/2009. Dispositivo para a aquisição e processamento de dados para determinação da massa corporal (Device for acquiring and processing data for determination of body mass). In Boletim de Propriedade Industrial no. 203/2009. Lisbon, Portugal.

8. Fidanza F (1991) Nutritional Status Assessment. London: Chapman \& Hall.

9. Marfell-Jones M, Olds T, Stewart A, et al. (2006) International Standards for Anthropometric Assessment. Potchefstroom: International Standards for Anthropometric Assessment.

10. Jelliffe DB, Jelliffe EFP, Zerfas A, et al. (1989) Anthropometry: general. In Community Nutritional Assessment With Special Reference to Less Technically Developed Countries, pp. 56-79 [DB Jelliffe, editor]. Oxford: Oxford University Press.

11. Norton $\mathrm{K} \&$ \& Olds $\mathrm{T}$ (1996) Measuring techniques in anthropometry - anthropometry equipment. In Anthropometrica, pp. 29-32. Sydney, NSW: University of New South Wales Press.
12. The World Medical Association (2008) Declaration of Helsinki - ethical principles for medical research involving human subjects. http://www.wma.net/en/30publications/ 10policies/b3/index.html

13. Peterson MJ, Czerwinski SA \& Siervogel RM (2003) Development and validation of skinfold-thickness prediction equations with a 4-compartment model. Am J Clin Nutr 77, 1186-1191.

14. Visser M, van den Heuvel E \& Deurenberg P (1994) Prediction equations for the estimation of body composition in the elderly using anthropometric data. Br J Nutr 71, 823-833.

15. Brozek J, Grande F, Anderson T, et al. (1963) Densitometric analysis of body composition: revision of some quantitative assumptions. Ann N Y Acad Sci 26, 113-140.

16. Coin A, Sergi G, Minicuci N, et al. (2008) Fat-free mass and fat mass reference values by dual-energy X-ray absorptiometry (DEXA) in a 20-80 year-old Italian population. Clin Nutr 27, 87-94.

17. Bland JM \& Altman DG (1986) Statistical methods for assessing agreement between two methods of clinical measurement. Lancet 1, 307-310.

18. Burgert SL \& Anderson CF (1979) A comparison of triceps skinfold values as measured by the plastic McGaw caliper and the Lange caliper. Am J Clin Nutr 32, 1531-1533.

19. Lohman TG, Pollock ML, Slaughter MH, et al. (1984) Methodological factors and the prediction of body fat in female athletes. Med Sci Sports Exerc 16, 92-96.

20. Stewart AD \& Hannan WJ (2000) Prediction of fat and fatfree mass in male athletes using dual X-ray absorptiometry as the reference method. J Sports Sci 18, 263-274.

21. Johansson AG, Forslund A, Sjödin A, et al. (1993) Determination of body composition-a comparison of dual-energy X-ray absorptiometry and hydrodensitometry. Am J Clin Nutr 57, 323-326.

22. Sardinha LB, Lohman TG, Teixeira PJ, et al. (1998) Comparison of air displacement plethysmography with dual-energy X-ray absorptiometry and 3 field methods for estimating body composition in middle-aged men. Am J Clin Nutr $\mathbf{6 8}$, 786-793.

23. Haapala I, Hirvonen A, Niskanen L, et al. (2002) Anthropometry, bioelectrical impedance and dual-energy X-ray absorptiometry in the assessment of body composition in elderly Finnish women. Clin Physiol Funct Imaging 22, 383-391.

24. Ravaglia G, Forti P, Maioli F, et al. (1999) Measurement of body fat in healthy elderly men: a comparison of methods. J Gerontol A Biol Sci Med Sci 54, M70-M76. 